\title{
Drivers of depopulation and spatial interdependence in a regional context
}

\author{
L. Alamá-Sabater ${ }^{\mathrm{a}, *}$, V. Budía ${ }^{\mathrm{a}}, \mathrm{N}$. Roig-Tierno ${ }^{\mathrm{b}}$, J.M. García-Álvarez-Coque ${ }^{\mathrm{b}}$ \\ ${ }^{\text {a }}$ Department of Economics and Local Development Institute (IIDL), University Jaume I, Castelló de la Plana, Spain \\ ${ }^{\mathrm{b}}$ Universitat Politècnica de València, Dep. of Economics and Social Sciences, Spain
}

\section{A R T I C L E I N F O}

\section{JEL classification:}

J18

R11

C21

Keywords:

Population decline

Urbanization

Spatial connections

Territorial development

Migration

\begin{abstract}
A B S T R A C T
There is a growing consensus on the need to propose specific policies to tackle the ongoing population decline in extensive rural areas of Southern Europe. Developing policies to target this issue requires assessment of the spatial, economic and structural conditions that explain why a municipality experiences depopulation. This study explores the drivers of population growth in the municipalities of the Mediterranean region officially known as the Comunitat Valenciana in Spain. This region is relatively urbanized, so the study allows to explore the spatial interdependence between municipalities that belong to urban and rural areas, some of them subject to significant depopulation. The study's findings, based on a spatial approach, help explain the population growth of municipalities based on their interdependence with neighbouring communities. A population growth model is defined drawing on several dimensions related to population dynamics: accessibility, economic conditions, public facilities and services, natural amenities, and degree of urbanization. The findings show that population dynamics in a given municipality are influenced by its surrounding municipalities, suggesting that policies focusing on clusters of local administrative units can be central to prevent the depopulation of certain areas.
\end{abstract}

\section{Introduction}

The present study helps tackle the understanding of population dynamics in local areas by considering not only the key drivers in municipalities but also the interdependence between surrounding municipalities. A spatial population growth model is specified to explore the influence of three factors discussed in the literature and identified by regional policymakers as drivers of demographic change: accessibility, economic conditions, and public facilities and services. We propose a population growth model to explore the conditions that explain population increase or decline in municipalities in a regional context where urban and rural municipalities coexist. Furthermore, the model is able to assess to what extent demographic decline can be observed as a localised issue or whether it is the reflection of spatial interdependence between neighbouring municipalities. While many local development studies pay attention to the characteristics of territories and their endogenous development, our focus is extended to a wider territorial approach that considers spatial influences from surrounding areas.

Demographic challenges are a concern in Europe and are the focus of political debate on future regional and rural policies in the European Union (Amcoff \& Westholm, 2007; Burholt \& Dobbs, 2012; Collantes \&
Pinilla, 2004; Ferry \& Vironen, 2011). The debate addresses the question of what kind of territorial policies could target isolated local communities that lag behind others to guarantee equal provision of services and basic citizens' rights (European Parliament, 2018). Discussion has spread to specific regional contexts and has affected not only predominantly rural regions but also relatively urbanized areas where communities at high risk of depopulation border highly populated areas.

In Spain, population decline in rural areas is now considered a major issue, reflected by the creation of a Special Commission in Spanish Congress and a specific General Secretary in the Central Government with a recent discussion regarding a national strategy to tackle population ageing and depopulation in large parts of Spain (Gobierno de España, 2019). In terms of population distribution, $54.8 \%$ of the country's area is inhabited by just $5.4 \%$ of the population (Burillo et al., 2019). Whereas depopulation in the second half of the 20th century was driven by interregional and international outflows of rural migrants, in the first decade of the present century, it was influenced by an inflow of foreign migrants attracted by economic growth (Collantes et al., 2014). Nowadays, population shifts are more intraregional and are shaped by natural growth (Collantes \& Pinilla, 2011; Pinilla et al., 2008). This recent process suggests the need to explore local situation in the present

\footnotetext{
* Corresponding author.

E-mail addresses: alama@uji.es (L. Alamá-Sabater), budi@uji.es (V. Budí), norat.roig@upv.es (N. Roig-Tierno), jmgarcia@upvnet.upv.es (J.M. García-ÁlvarezCoque).
} 
analysis. Accordingly, local and regional policymakers play an important role in influencing population dynamics through local or interterritorial political decisions that affect regional development.

What interests to the present contribution is the evaluation on how demographic changes, with a dramatic decline in some municipalities, are widened by spatial dependence relationships that exist between municipalities and spillover effects across neighbouring areas. Authors as Boarnet (1994) and Firmino et al. (2017), de Graaff (2012a, 2012b), among others, have used spatial econometric approaches to study interactions between neighbouring areas. Feser and Isserman (2007), Henry, M. S., Schmitt, B. and Piguet, V. (2001), Henry, M.S., Schmitt, B., Kristensen, K., Barkley, D, L. and Bao, S. (1999) delve on interterritorial analysis and focus their attention in rural-urban connections and the urban spillovers that spread on rural areas.

Our contribution proposes a specification that isolates direct and indirect effects that allow to explain the differential behaviour of municipalities at heavy risk of population decline. While interterritorial cooperation policies are a policy concern in European countries, what it is less known is the extent to which spillover effects of neighbouring municipalities affect a given community's population dynamics, compared to the local direct effects of regional development policies. Therefore, a major contribution of this article is to test and measure the impact of drivers of demographic change at the municipal level, adding the influence of neighbouring area. Consequently, our findings support the need for territorial policies that face the demographic decline from a spatial point of view, that is to say, not only considering the specific declining municipalities but also their surrounding areas.

Data on all municipalities in a specific region of Southern Europe (Valencia) regardless of whether they are rural or urban, are used in this study to assess the specific factors that explain population dynamics as a case study where urban and rural areas coexist. The results can enrich our knowledge and support the design of policies to influence population dynamics in areas with depopulation problems. This study also contributes by estimating the indirect spatial effects of changes in the variables, thereby capturing the differences between municipalities with different levels of depopulation risk.

We examine the Region of Valencia (officially and hereafter referred to as the Comunitat Valenciana), which is a Spanish NUTS 2-level region located on the east coast of the Iberian Peninsula next to the Mediterranean Sea (518 km of coastline). The population of the Comunitat Valenciana is 5 million, which equates to $11 \%$ of the Spanish population, making it the fourth most populous region in Spain. The regional government is in charge of healthcare, education and regional policy, and local government presides over the region's 542 municipalities. Of these, 157 are considered at risk of depopulation (Generalitat Valenciana, 2017a). Population decline is a prominent issue in regional policy designed to promote an anti-depopulation strategy. The regional public administration (Generalitat Valenciana) has selected specific indicators to define the drivers of depopulation risk. ${ }^{1}$

The paper is organized as follows. Section 2 details the conceptual framework and the methodology of the demographic spatial model. Section 3 presents the demographic characteristics and the regional data of Comunitat Valenciana, with the measurement of the main variables describing the main drivers of population growth. The estimation and discussion of the model's coefficients and the direct and indirect spatial effects are showed in Section 4 and in Section 5 is offered the conclusions and policy implications for regional policies that face demographic challenges.

\footnotetext{
1 The regional Government of the Comunitat Valenciana (Generalitat Valenciana, 2017a) classified certain municipalities as being at risk of depopulation. The classification was based on three indicators comprising variables measuring accessibility, public facilities and economic conditions.
}

\section{Conceptual framework and methodology}

\subsection{Conceptual approach}

We will start with proposing a growth model that, by considering all municipalities in the studied region, presents population growth as a function of a series of drivers suggested in the literature. The literature on population change has largely focused on determining its most relevant drivers. Socioeconomic variables and natural amenities are some of the variables identified by scholars, so our model will take into account some variables reflecting income, labour market and natural endowments. Lundberg (2002) and Glaeser et al. (2003) consider local income as a major determinant of population change, while Glaeser et al. (1995) examined the socioeconomic drivers of growth of U.S. cities in different periods. Graves $(1979,1983)$, Graves and Linneman (1979) and Chi and Marcouiller (2011) stressed that natural amenities such as landscapes, open space, climates, forests and so forth are important resources that attract the local population and economic activities. Authors as Cushing (1987); Shields et al. (2005) and more recently, Firmino et al. (2017) have provided evidence that population movements depend on both natural amenities and economic conditions. Delfmann et al. (2014) focused on the causes of population decline, underscoring the spatial distribution of employment and economic opportunities as key factors to explain population growth. Similarly, Polèse and Shearmur (2006) analysed population decline in five Canadian regions by considering local economic factors. Chi and Marcouiller (2011) further extend the analysis of population determinants and provided an extensive list of population determinants grouped into four categories: demographic characteristics, socioeconomic conditions, transport accessibility, and the potential for land conversion and development.

Other scholars suggest combined socioeconomic variables with quality of life indicators to analyse the main determinants of population movements. In most cases the quality of life has been measured as an indicator composed by different variables related with accessibility, natural amenities and other territorial characteristics. It is the case of Clark et al. (1988), Glaeser et al. (2001), Glaeser and Shapiro (2003), Shapiro (2006), Cheshire and Magrini (2006, 2009), Portnov and Schwartz (2008), Delfmann et al. (2014), Royuela et al. (2010); Royuela (2011), Royuela et al. (2003) and others. In our model, we consider the access to major urban centres, the availability of public services and facilities, and the degree of urbanization of the municipality, considering this an indicator of access to knowledge and to private services.

In this article, we assume that there is a spatial interdependence between municipalities and that it can be significant in some regions where there can be a strong urban influence. This is the case of large parts of Spain and other European countries, where urban areas may grow at the expense of rural areas. Our model be able to deal with population growth as well as decline, which gives further insight into the impact of certain drivers of modern migration flows and population change (Camarero \& Sampedro, 2019; Collantes et al., 2014).

In addition, regional studies have also tackled population growth issues considering interterritorial connections. The spatial relation between geographical areas is, as mentioned in this article's introduction, one of our main concerns. As indicated in the introduction, there is a wide literature that considers that population movements take place not only as a result of characteristics of the own municipalities, but also of surrounding's areas which constitute local labour areas that allow an insider population movement. Neighbourhood effects must be a core part of the modelling approach. At the local level, population flows between regions are not expected to be independent; instead, community dynamics are expected to be influenced by each other. The transfer of people working, studying or using public infrastructures across different municipalities makes the dependence on the population dynamics of nearby regions a reality (Jedwab et al., 2017). This process is 
consistent with studies that have introduced spatial connections as an additional determinant of population changes (Chi \& Zhu, 2008; Delfmann et al., 2014; Firmino et al., 2017; Han et al., 2016; Lunberg, 2002; Pacheco \& Tyrrell, 2002). The relationship of population dynamics in space reflects spillover effects and therefore the causal relationship between certain explanatory variables and population growth in neighbouring municipalities. Policymakers should consider these indirect effects in policy decisions to tackle depopulation in certain regions (Boarnet et al., 2005). Spatial heterogeneity is a common feature of the spatial distribution of data. It refers to the unequal distribution of a variable across a spatial unit of reference (Anselin, 1988). If the model estimation does not deal with spatial dependence and heterogeneity, the estimated parameters will be biased.

\subsection{Growth model}

Let us consider a theoretical framework that relates the population change in a given municipality $i$ with a series of variables describing productivity and quality of life indicators. For this we initially draw on the growth model developed by Glaeser et al. (1992) and adapted by Glaeser et al. (1995). Accordingly, the total output of a municipality is given by:

$A_{i, t} f\left(L_{i, t}\right)=A_{i, t} L_{i, t}^{\sigma}$

In Eq. (1), $A_{i, t}$ is the level of productivity of municipality $i$ at time $t$, $\mathrm{L}_{\mathrm{i}, \mathrm{t}}$ denotes the population of municipality i at time $\mathrm{t}, f\left(L_{i, t}\right)$ is the common Cobb-Douglas production function across cities and $\sigma$ is a region-wide production parameter. The total utility of individuals (Eq. (4)) is given by the product of wages $\left(\mathrm{W}_{\mathrm{i}, \mathrm{t}}\right)$ and a quality of life index which depends on population $(\delta>0)^{2}$ (Glaeser et al., 1995).

$\mathrm{W}_{\mathrm{i}, \mathrm{t}}=\sigma A_{i, t} L_{i, t}^{\sigma-1}$

Quality of life index $=Q_{i, t} L_{i, t}^{-\delta}$

Utility $=\sigma A_{i, t} L_{i, t}^{\sigma-1} Q_{i, t} L_{i, t}^{-\delta}=\sigma A_{i, t} L_{i, t}^{\sigma-\delta-1} Q_{i, t}$

Eq. (4) can be rewritten in terms of growth rates between two periods 0 and $t$ as:

$\log \left(\frac{U_{t}}{U_{0}}\right)=\log \left(\frac{A_{i, t}}{A_{i, 0}}\right)+\log \left(\frac{Q_{i, t}}{Q_{i, 0}}\right)+(\sigma-\delta-1) \log \left(\frac{L_{i, t}}{L_{i, 0}}\right)$

In the model, productivity and quality of life are considered as functions of a vector of local areas' characteristics at time $0\left(X_{i, 0^{\prime}}\right)$ :

$\log \left(\frac{A_{i, t}}{A_{i, 0}}\right)=X_{i, 0}^{\prime} \alpha+\varepsilon_{i, t}$

$\log \left(\frac{Q_{i, t}}{Q_{i, 0}}\right)=X_{i, 0}^{\prime} \theta+\xi_{i, t}$

Rearranging Eq. (5), the population growth of municipality $i$ is determined by characteristics of the municipality $\left(X_{i, o} o^{\prime}\right)$, some of them associated with productivity and others with quality of life indicators (Glaeser \& Shapiro, 2003; Royuela et al., 2010):

$\log \left(\frac{L_{i, t}}{L_{i, 0}}\right)=\frac{1}{1+\delta-\sigma} X_{i, 0}^{\prime}(\alpha+\theta)+\chi_{i, t}=\beta X_{i, 0}^{\prime}+\chi_{i, t}$

where $\chi_{i, t}$, is the error terms that include elements of productivity $\left(\varepsilon_{i, t}\right)$ and quality of life $\left(\xi_{i, t}\right)$ of municipalities that are missing in the vector of local characteristics. $\beta$ is the parameter that summarize productivity and

\footnotetext{
${ }^{2} \delta$ is the elasticity of population in relation to quality of life. It is presumed to be positive indicating that if population increases there are other factors as population congestion that make quality of life decrease.
}

quality of life estimates. ${ }^{3}$

Based on the theoretical model specified in Eq. (8), a population growth equation can be proposed as:

$$
\begin{aligned}
\text { popgrowth }_{i}= & \beta_{0}+\beta_{1} \text { pop }_{i}+\beta_{2} \text { ageing }_{i}+\beta_{3} \text { contracts }_{i} \\
& +\beta_{4} \text { income }_{i} \\
& +\beta_{5} \text { facilities }_{i}+\beta_{6} \text { access }_{i}+\beta_{7} \text { urbanization }_{i} \\
& +\beta_{8} \text { natura }_{i}+u_{i}
\end{aligned}
$$

where popgrowth $h_{i}$ is the population growth in municipality i between periods 0 and $\mathrm{t}$; pop $_{i}=$ initial population in period 0 ; ageing $_{i}$ ratio of senior population with respect to young population; contracts $_{i}=$ index of job opportunities; income $_{i}=$ income per capita; facilities $_{i}=$ index of public facilities and services; $a c c e s s_{i}=$ distance to the nearest city or urban cluster; urbanization $_{i}=$ urban or rural categorization of municipality i; natura $_{i}=$ index of natural and protected areas. ${ }^{4}$

\subsection{Spatial model}

Once the basic specification of the growth model has been established, Eq. (9) can be extended to account for population dynamics in neighbouring regions. Spatial econometric theory offers tests to check whether the data are spatially correlated. The most commonly used is spatial exploratory data analysis (ESDA) based on global and local indicators. Specifically, Moran's I statistic and LISA clusters maps are the most widely used ${ }^{5}$ and provide a preliminary test of spatial dependence between local administrative units.

The arrangement of units in space relative to their neighbours is described through the square weight matrix (W). Most empirical studies have used this structure based on the exogenous geographical characteristics. Distance between regions, k-nearest regions and the common border criterion are the definitions of neighbourhood that are most widely used in the literature. In this study, to ensure the robustness of the results, the notion of neighbourhood was applied in terms of two different geographical structures:

First-order border:

$w_{i, j}=\left\{\begin{array}{c}1 \text { if } i \text { and } j \text { share a common border of first order } \\ 0 \text { if } i \text { and } j \text { do not share a common border of first order or if } i=j\end{array}\right\}$

Inverse-square matrix:

$w_{i, j}=\left\{\begin{array}{c}\frac{1}{d^{2}}, \text { where d represents distance between municipality } i \text { and } j \\ 0 \text { if } i=j\end{array}\right\}$

The weight matrix is a square matrix, with $\mathrm{n} * \mathrm{n}$ dimension ( $\mathrm{n}$ is the number of spatial units) and is usually row-standardised, so each row of W sums to the unit.

The population growth model of Eq. (9) can be extended by using a

$3 \chi_{i, t+1}=\frac{\left[\left(-\log \frac{U_{i, t+1}}{U_{i, t}}\right)+\varepsilon_{i, t+1}+\xi_{i, t+1}\right]}{(1+\delta-\sigma)}, \beta=\frac{(\alpha+\theta)}{1+\delta-\sigma}$.
${ }^{4}$ All variables are described in Table 1.
${ }^{5} I_{i}=n \frac{\sum_{i=1}^{n} \sum_{j=1}^{n} w_{i j}\left(y_{i}-\bar{y}\right)\left(y_{j}-\bar{y}\right)}{S_{0} \sum_{i=1}^{n}\left(y_{i}-\bar{y}\right)^{2}}$, being $y_{j}$ the population change of municipality $i$ $(j), \bar{y} \bar{y}^{\mathrm{t}}$ indicates the sample mean of the population change, $w_{i j}$ represents the spatial connection between municipality $i$ and municipality $j$ in the spatial weight matrix $\mathrm{W}$, and $S_{0}=\sum_{i=1}^{n} \sum_{j=1}^{n} w_{i j} \mathrm{~S}_{0}=\sum_{\mathrm{i}=1}^{\mathrm{n}} \sum_{\mathrm{j}=1}^{\mathrm{n}} \mathrm{w}_{\mathrm{ij}}$ is a standardisation factor corresponding to the sum of the weights. 


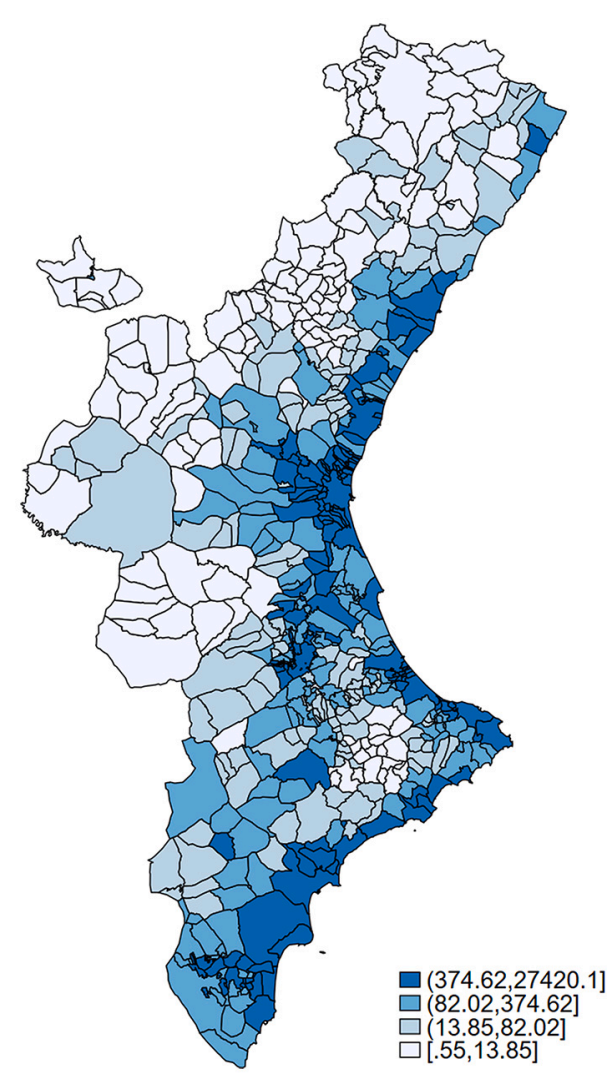

Fig. 1. Population density distribution in Valencian municipalities. Source: Compiled by the authors based on data from the Spanish Statistics Institute (INE). The maps show four classes of population densities (in brackets).

spatial autoregressive model (SAR) and a spatial error model (SEM). ${ }^{6}$ In the SAR specification (Eq. (12)), it is assumed a dependence structure forms with the endogenous variable. In the SEM specification (Eq. (13)), non-observable elements are included in the error term. Non-observable effects can be linked to neighbouring regions as well as intangible characteristics related to culture, social behaviour, and other aspects:

$$
\begin{aligned}
\text { popgrowt }_{i}= & \beta_{0}+\rho \text { Wpopgrowt }_{i}+\beta_{1} \text { pop }_{i}+\beta_{2} \text { ageing }_{i}+\beta_{3} \text { contracts }_{i} \\
& +\beta_{4} \text { income }_{i}+\beta_{5} \text { facilities }_{i}+\beta_{6} \text { access }_{i}+\beta_{7} \text { urbanization }_{i} \\
& +\beta_{8} \text { natura }_{i}+u_{i}
\end{aligned}
$$

$$
\begin{aligned}
\text { popgrowth }_{i}= & \beta_{0}+\beta_{1} \text { pop }_{i}+\beta_{2} \text { ageing }_{i}+\beta_{3} \text { contracts }_{i}+\beta_{4} \text { income }_{i} \\
& +\beta_{5} \text { facilities }_{i}+\beta_{6} \text { access }_{i}+\beta_{7} \text { urbanization }_{i}+\beta_{8} \text { natura }_{i}+u_{i}
\end{aligned}
$$

In Eq. (12), Wpopgrowth $_{i}$ indicates the population change in municipality $i$ 's neighbouring municipalities (spatial lag of dependent variable). The error term of Eq. (13) is enhanced to include the nonobservable effects of neighbouring areas captured by matrix W.

\footnotetext{
${ }^{6}$ Other spatial specifications were tested, such as DURBIN (lag variables in dependent and explanatory variables), SLX (spatial lag variables on explanatory variables) and SARMA (spatial dependence in endogenous variables and error terms) but estimation results were not satisfactory.
}

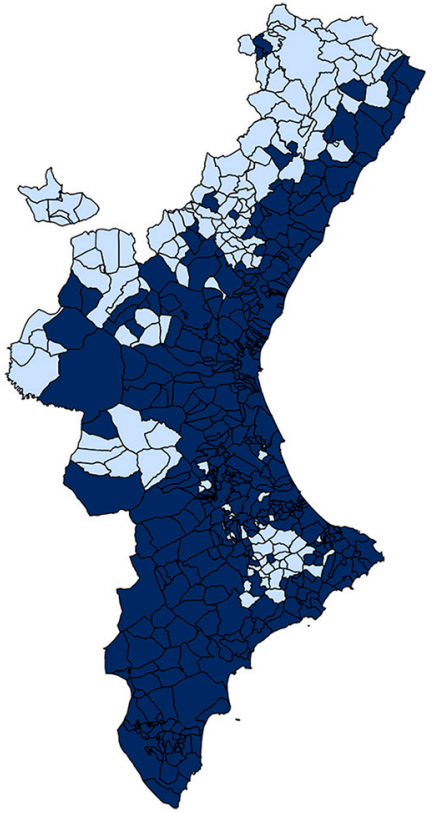

Depopulation no risk Depopulation risk

Fig. 2. Valencian municipalities with depopulation risk.

Source: Compiled by the authors based on data from the local administration. See Annex and Generalitat Valenciana (2017a).

\section{Demographic trends and data}

The demographic landscape of the Comunitat Valenciana is defined by a pattern of density where urban areas are located mainly on the coast, and rural areas in the interior and more hilly areas. Fig. 1 indicates population density distribution along Valencian municipalities. It confirms the high population density of coastal municipalities. ${ }^{7}$ In contrast, many inland communities have a low population density. Only $40 \mathrm{~km}$ inland from the coast, the depopulation of certain communities is a serious problem that authorities are starting to tackle. The population in such areas lies below the critical threshold to maintain certain services.

Given the Comunitat Valenciana's dual identity of being home to both rural and urban areas, one of the aims of the regional government has been to design policies that are tailored to the degree of urbanization of each municipality. The Valencian Government after a consultation to local stakeholders, built a system of local indicators to classify municipalities according to their depopulation risk (Annex), besides three drivers of population dynamics have been considered: economic conditions, public equipment and facilities and services (Generalitat Valenciana, 2017a).

Considering this study, the regional administration estimates that the number of municipalities at risk of depopulation ${ }^{8}$ is 157 (Fig. 2). These municipalities suffered a population loss of $14.5 \%$ between 1996 and 2016. These changes contrast with the general trend of the whole region, which experienced population growth of $24 \%$ over this period (Generalitat Valenciana, 2017a; Alamá-Sabater et al., 2019).

Drawing on this approach, we propose a population growth model using as dependent variable the population growth of the 542 municipalities in the Comunitat Valenciana over the period 2010 to 2019. For the explanatory variables of the model, the economic conditions are measured by employment opportunities (measures as the total number of labour contracts per capita) and income per capita. Accessibility is defined as the distance to the nearest urban cluster, according to the

\footnotetext{
7 Provinces' capitals are on the coast, with their metropolitan area.

${ }^{8}$ See criteria used for defining depopulation risk in Annex and Alamá-Sabater et al. (2019).
} 
Table 1

Description of variables.

\begin{tabular}{|c|c|c|c|}
\hline Variable & Description & Source & $\begin{array}{l}\text { Sign of expected } \\
\text { impact }\end{array}$ \\
\hline popgrowth & $\ln ($ pop2019/pop2010) & Spanish National Statistics Institute (INE) & $\begin{array}{l}\text { Dependent } \\
\text { variable }\end{array}$ \\
\hline pop10 & $\ln ($ pop2010) & Spanish National Statistics Institute (INE) & $+1-$ \\
\hline ageing & $\begin{array}{l}\text { Population }>64 \text { years divided by } \\
\text { population }<16 \text { years }(2010)\end{array}$ & $\begin{array}{l}\text { Spanish National Statistics Institute (INE) and Local Government of Sustainable Economy, } \\
\text { Productive Sectors, Trade and Work (Generalitat Valenciana, 2017b) }\end{array}$ & - \\
\hline Contracts & ln (number of labour contracts in 2010 ) & Local Government of Employment and Training Service (Generalitat Valenciana, 2017b) & + \\
\hline Income & $\begin{array}{l}\text { In (income per capita in } 2010 \text { in } \\
\text { thousands of Euros) }\end{array}$ & $\begin{array}{l}\text { Local Government of Sustainable Economy, Productive Sectors, Trade and Work (Generalitat } \\
\text { Valenciana, 2017b) }\end{array}$ & + \\
\hline Access & Distance to the nearest urban cluster & Degree of Urbanization (DEGURBA) EUROSTAT (2019) & - \\
\hline Facilities $^{\mathrm{a}}$ & Public facilities and services & Local administration (Generalitat Valenciana, 2017a) & + \\
\hline Urbanisation $^{\mathrm{b}}$ & Urban, intermediate or rural area & Degree of Urbanization EUROSTAT (2019) & - \\
\hline Natura & Number of natural and protected areas & $\begin{array}{l}\text { Local administration of agricultural, local development, climatic emergency and ecologic } \\
\text { transition }\end{array}$ & - \\
\hline
\end{tabular}

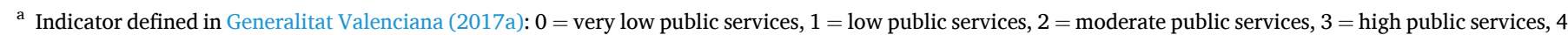
$=$ very high public services.

b The DEGURBA project classifies Local Administrative Units in urban =1; intermediate = 2; rural = 3 (Dijkstra \& Poelman, 2014; Eurostat, 2019).

Source: Compiled by the authors.

Table 2

Descriptive statistics.

\begin{tabular}{lcccc}
\hline & Mean & Std. dev. & Min. & Max. \\
\hline popgrowth & -0.0690 & 0.114 & -0.497 & 0.375 \\
pop10 & 9431.19 & $41,093.2$ & 16 & 809,267 \\
ageing & 243.7 & 354.7 & 37.6 & 5500 \\
Contracts & 240,991 & 14,996 & 3 & 322,117 \\
Income & $12,458.47$ & 1726.364 & 6319 & 21,963 \\
Access & 27.763 & 22.28 & 0 & 116.787 \\
Natura & 1.5 & 2.2 & 0 & 16 \\
\hline
\end{tabular}

Source: Compiled by the authors from data described in Table 1.

degree of urbanization classification (DEGURBA, Eurostat, 2019). ${ }^{9}$ Public facilities are measured using the indicator developed by in Generalitat Valenciana (2017a) expressing access to public services (schools and hospitals). We have added other control variables as the percentage of aged population, the total of natural and protected areas in each municipality ${ }^{10}$ and an indicator of the degree of urbanization of municipalities, following the quoted Eurostat criteria (Eurostat, 2019) ${ }^{11}$ indicating access to private services, economies of agglomeration and knowledge. Table 1 presents the complete list of variables (dependent and explanatory) and displays their definition, sources and expected impact on population growth. Descriptive statistics for all variables are provided in Table 2. Our main interest is to test the relevance of accessibility, economic conditions and public facilities and services on population dynamics, distinguishing between direct and indirect spatial effects. The results obtained allow to narrow down the focus of the territorial policy that is being carried out by the regional and local administrations.

We analysed global and local spatial distribution of the population

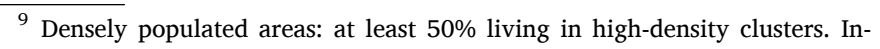
termediate density areas: less than $50 \%$ of the population living in rural grid cells and less than $50 \%$ living in a high-density cluster. Thinly populated areas: more than $50 \%$ of the population living in rural grid cells. A cluster of contiguous grid cells of $1 \mathrm{~km} 2$ (including diagonals) with a population density of at least 300 inhabitants per $\mathrm{km} 2$ and a minimum population of 5000 (Eurostat, 2019, p. 30).

${ }^{10}$ Including: natural parks, nature reserve, natural monuments and protected municipal landscapes in general.

11 https://ec.europa.eu/eurostat/web/gisco/geodata/reference-data/populati on-distribution-demography/degurba. See also Dijkstra and Poelman (2014).
}

growth of our database, using a neighbourhood criterion based on the spatial matrix. For the sake of brevity, only the results of the spatial connections based on inverse-square distance (Eq. (11)) are shown. ${ }^{12}$

Fig. 3 shows the scatter plot represented by the Moran's I statistic for population growth in municipalities of the region in the studied period. The value 0.267 (p-value $=0.0010$ ) indicates that population growth is not randomly distributed and that, instead, the positive value indicates that nearby regions tend to have similar tendencies (growth or decline) on population dynamics.

Fig. 4 determines the presence of regional clusters and the type of cluster. The clusters are classified as such when the value at a location (either high or low) is more similar to its neighbours' average than would be the case under spatial randomness. Fig. 4 indicates 64 highhigh clusters, that is, municipalities with high population growth surrounded by neighbours with high population growth and 54 low-low clusters, municipalities with low population grow values surrounded by municipalities with low population growth. High-Low and Low-High are classified as spatial outliers' points. ${ }^{13}$

\section{Results and analysis}

The strategy to select the model that best fits to the spatial structure is determined using the Lagrange multiplier (LM) test for a spatially lagged dependent variable (LM spatial lag) and the spatial autocorrelated error term (LM spatial error), proposed by Anselin and Bera (1998). These tests are based on the estimation of the model under the null hypothesis of OLS results. According to this strategy, the selected model is the one with the most significant statistic (Anselin, 2017). Table 3 shows the results of the diagnostic test calculated for two spatial connective structures, using OLS model: first-order border and inversesquare distance. ${ }^{14}$ For both spatial structures, the results support the rejection of the null hypothesis of no spatial autocorrelation, although the value for the LM spatial lag is higher than for the LM spatial error. In this case, the selection strategy indicates that the spatial model that fits better with the spatial structure is the SAR specification, although, in

\footnotetext{
12 Other alternative definitions of the spatial weight matrix were used with binary matrices that take 1, 4 or 6 nearest neighbour municipalities. The results were similar to those presented in the paper, so they have been omitted for the sake of brevity.

13 https://geodacenter.github.io/download.html.

14 For the sake of simplicity, we have included the spatial structure based on the first order common border contiguity and the square-inverse distance, although we also tested the estimation using other weight matrices based on other orders' common variables, k-distances and k-nearest municipalities.
} 


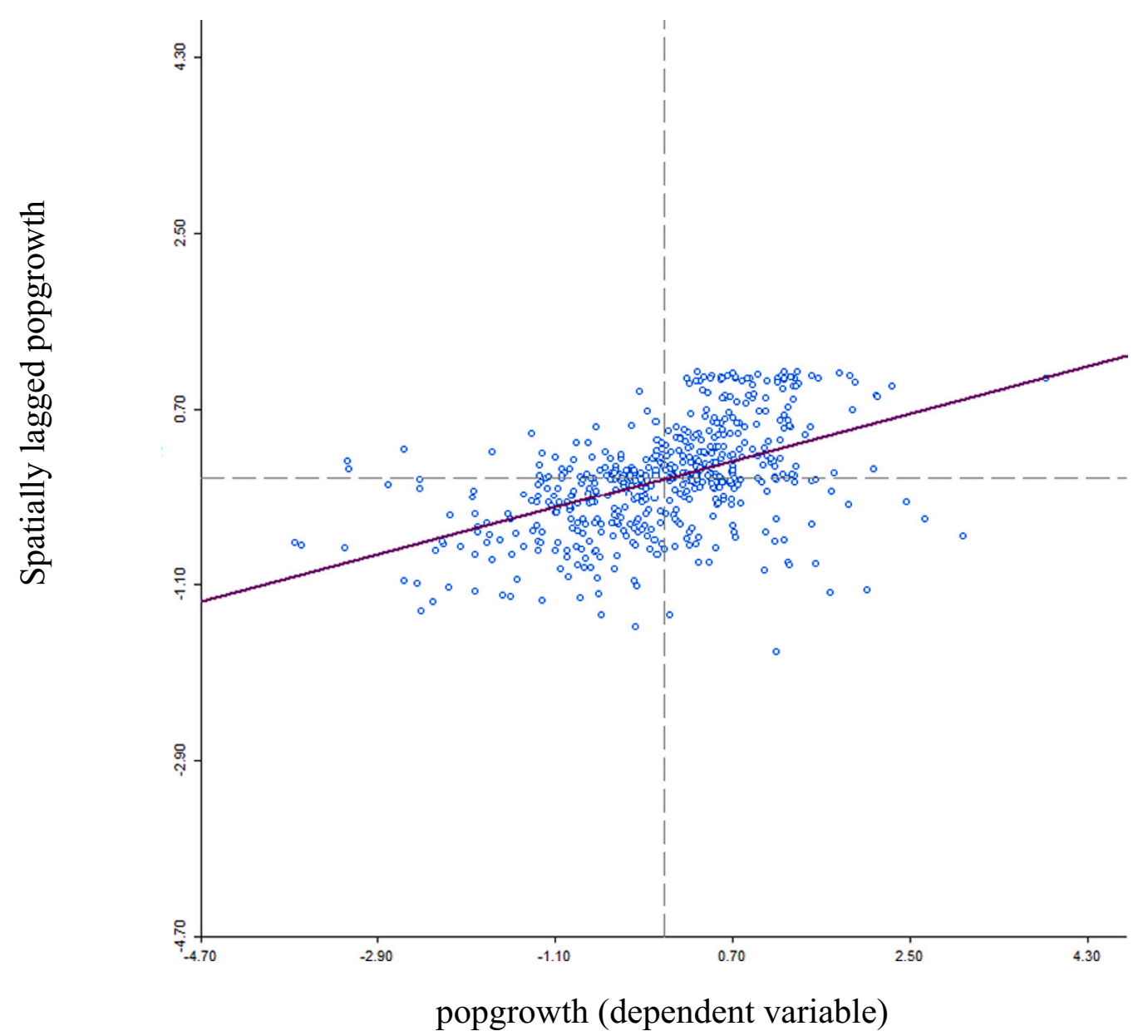

Fig. 3. Moran's I (inverse-square distance matrix).

(Moran's $I=0.267$ p-value $=0.0010$ ).

Source: Compiled by the authors.

order to incorporate robustness in the results, we have estimated the two models.

Table 3 displays the estimation results of models presented in Eqs. (12) and (13) by a Maximum Likelihood Estimation approach. Columns 2 and 3 show the estimates for a spatial autoregressive model (SAR) using two different weight matrices: first-order common border and inverse-square distance. In Columns 4 and 5, the estimation corresponds to a spatial autoregressive error model (SEM) model, with the same weight matrices. As Table 3 indicates, the spatial parameters $\rho$ and $\lambda$ are positive and significant in all cases, confirming the spatial dependence of population growth around neighbours' municipalities. The AIC criterion indicates that the model with the weight matrix calculated with an inverse-square distance has a lower value and therefore would be the more adequate estimation. In the same way, the likelihood highest value corresponds to the SAR model estimated with an inverse-square distance.

\subsection{Direct and indirect spatial effects}

As explained in the literature, the parameters of the estimation of a spatial autoregressive model (SAR) do not indicate the marginal effect of changing explanatory variables. ${ }^{15}$ The inclusion of the spatial lag of the endogenous variable generates direct and indirect effects on the

${ }^{15}$ In the SEM model, indirect effects are zero. dependent variable that should be considered in the results. In a SAR model, the partial derivative expression of a change in an explanatory variable is as follows:

$\frac{\partial Y}{\partial X_{k}}=\left(I_{n}-\rho W\right)^{-1} \beta_{k}$

Expression (14) represents a $n \times n$ matrix, where each element $(i, j)$ indicates the spatial spillover of municipality $i$ into municipality $j$, and the main diagonal $(i, i)$ captures the direct effects. Thus, the marginal effect of the change in the population in municipality $i$, as consequence of a change in the kth explanatory variable in municipality $j$, depends on $\beta_{k}, \rho$ and the W matrix (LeSage \& Pace, 2009). LeSage and Pace (2009) identified the total indirect effect as a scalar measure, which is the average of the off-diagonal row sum of the marginal effect's matrix. Total direct effects are the average sum of the main diagonal of matrix (Elhorst, 2010).

Table 4 presents the direct, indirect and total effects estimates for all variables. The results for the square inverse distance and first-order common border spatial structures show that for all variables, direct and indirect effects have significant impacts. The results indicate that a spatial approach helps understand how interactions between municipalities explain population changes. The last column shows the share of indirect effects on total effects for the square inverse distance matrix specification.

In reference to economic conditions represented by employment opportunities (number of labour contracts) and income per capita 

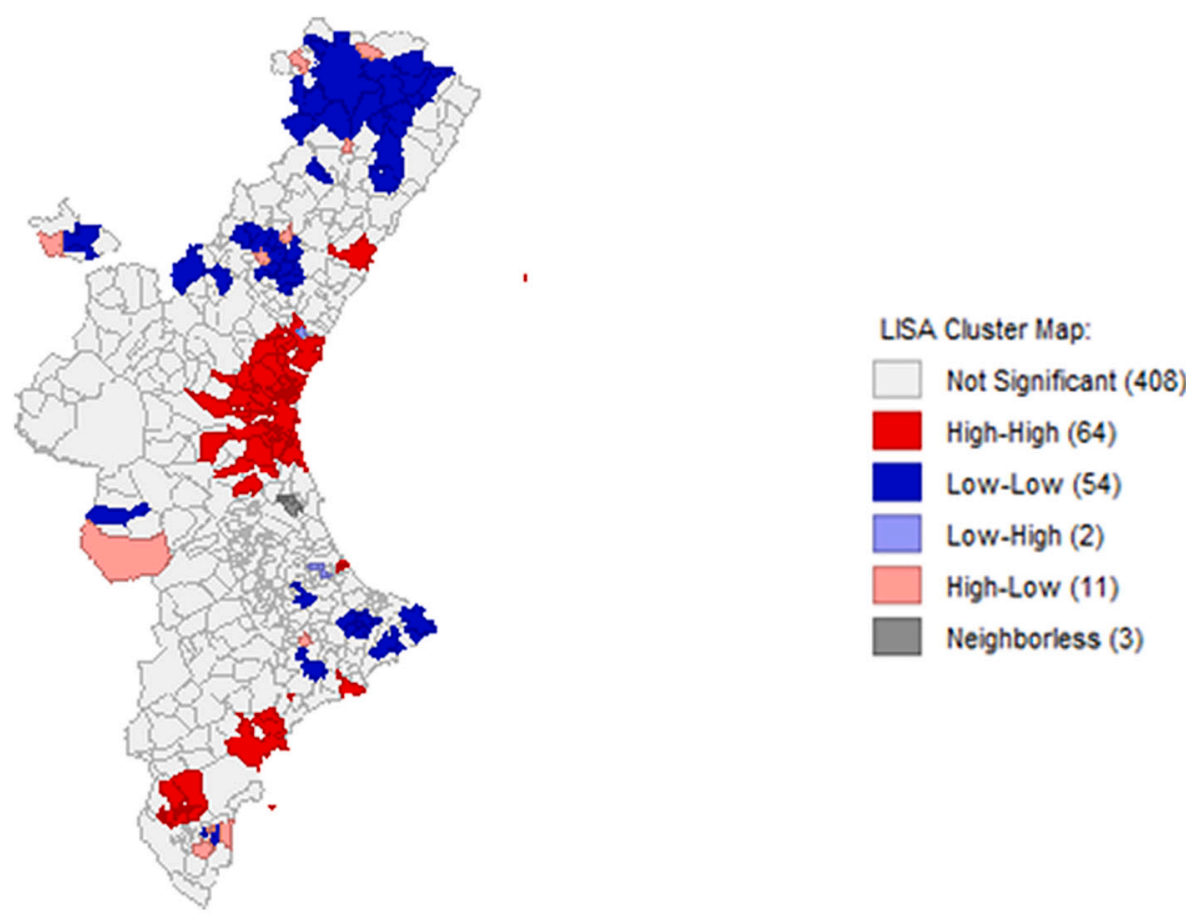

Fig. 4. LISA cluster map.

Source: Compiled by the authors based on data from the Spanish Statistics Institute (INE).

(income) Table 4 indicates that a $10 \%$ increase in contracts in own municipality and in its surroundings involves a population increase of $0.298 \%$ and $0.223 \%$, respectively. Similarity, the growth in population would be $1.384 \%$ if income per capita increases $10 \%$ in the same municipality, whereas if the change is done in the neighbouring area, the population increases by $1.033 \%$.

As expected, accessibility (access), measured as the distance to a semiurban hub, has a negative sign, suggesting that urban-rural linkages matter. Hence, municipalities near urban areas tend to experience positive population growth. Indirect effects indicate that accessibility in the surrounding area also has positive effects on population growth in certain municipalities. Table 4 shows that the ratio of indirect effects with respect to direct effects is higher for accessibility than for the other variables (46.15\%). As explained in Table 1, public facilities and services (facilities) are represented using an indicator comprised between 0 and 4 . The estimation results are as expected, with the positive sign indicating that an improvement of $10 \%$ in own municipalities involves a $0.148 \%$ increase in population growth, with an indirect effect of $0.110 \%$ if the improvement takes place in the surrounding municipalities.

In the case of degree of urbanization, the direct effects also have the expected sign, rural areas have lower population increases than municipalities with high degrees of urbanization. The negative and significant value of the indirect effects in this variable indicates that a higher urbanization in the surroundings has a positive effect on the population growth in a given municipality.

As regards to the population ageing index (ageing), the sign is as expected. The negative coefficient indicates that if the share of senior population increases, the local population tends to decline. For natural protected areas the value is negative: the higher number of natural areas in a municipality, the higher the population decline. This could reflect that natural areas are not perceived as an attribute that retains population and would need a further consideration as population in the rural areas could see protection more as a constrain than as an opportunity. For both ageing and natural area variables, indirect effects are also significant, reinforcing the importance of interterritorial connections at local area level.

Estimated coefficients in the SEM model (Table 3) indicate direct effects in line with the SAR model estimation. In the SEM model, the indirect effects are non-existent. These findings suggest that the factors selected by policymakers to prevent the demographic decline are consistent with the presented spatial growth model and explain population dynamics across municipalities. The observed direct effects confirm the territorial policies aiming at improving local accessibility, facilities and economic conditions. These results can help policymakers adapt the criteria used to define depopulation and weight the indicators using the marginal effects given by the estimation. Overall economic conditions, through income per capita, represent the most important driver, so economic conditions should have a greater weight than the other factors.

We are interested if the spillover effects across municipalities linked to a change in certain explanatory variables follow different patterns attending to the risk of depopulation of municipalities. For this analysis, we divided the database considering two groups of municipalities displayed in Fig. 2: with depopulation risk and without depopulation risk (Generalitat Valenciana, 2017a; Alamá-Sabater et al., 2019). ${ }^{16}$ Fig. 5 displays direct and indirect effects of explanatory variables on population growth. We have included the variables that represent economic conditions (contracts, income), accessibility (access) and facilities. We used the estimates based in the square inverse-distance matrix (Tong et al., 2013).

Fig. 5 reflects some noteworthy aspects. Firstly, direct effects are, on average, greater in municipalities without depopulation problems than direct effects observed in areas with depopulation problems. Secondly, indirect effects in municipalities with serious depopulation problems are, on average, higher than indirect effects in municipalities with no demographic decline, suggesting that the population dynamics in municipalities with depopulation risk benefit more from changes in

\footnotetext{
${ }^{16}$ We thank for a reviewer comment pointing out that according to matrix (10) and given that $\beta_{\mathrm{k}}$ is constant for all municipalities, differences in elasticities are due to matrix $\mathrm{W}$, instead to the distance between municipalities. However, we added this information to reflect the calculated differences between direct and indirect effects in both groups of municipalities.
} 
Table 3

Spatial models' estimates. SAR and SEM results with common border and square inverse distance weight matrices.

\begin{tabular}{|c|c|c|c|c|}
\hline \multirow[t]{2}{*}{ Variables } & (2) & (3) & (4) & (5) \\
\hline & SAR model First-order border & SAR model Inverse-square distance & SEM model First-order border & SEM model Inverse-square distance \\
\hline \multirow[t]{2}{*}{$\rho$} & $0.277^{* * *}$ & $0.435^{* * *}$ & & \\
\hline & {$[0.000]$} & {$[0.000]$} & & \\
\hline \multirow[t]{2}{*}{$\lambda$} & & & $0.301^{* * *}$ & $0.527^{* * *}$ \\
\hline & & & {$[0.000]$} & {$[0.000]$} \\
\hline \multirow[t]{2}{*}{ pop } & $-0.042^{* * *}$ & $-0.041^{* * *}$ & $-0.046^{* * *}$ & $-0.048^{* * *}$ \\
\hline & {$[0.000]$} & {$[0.000]$} & {$[0.000]$} & {$[0.000]$} \\
\hline \multirow[t]{2}{*}{ ageing } & $-0.026^{* * *}$ & $-0.027^{* * *}$ & $-0.029^{* * *}$ & $-0.030^{* * *}$ \\
\hline & [0.004] & {$[0.003]$} & {$[0.001]$} & {$[0.001]$} \\
\hline \multirow[t]{2}{*}{ contract } & $0.029 * * *$ & $0.029^{* * *}$ & $0.030^{* * *}$ & $0.033^{* * * *}$ \\
\hline & {$[0.000]$} & {$[0.000]$} & {$[0.000]$} & {$[0.000]$} \\
\hline \multirow[t]{2}{*}{ income } & $0.137^{* * *}$ & $0.136^{* * *}$ & $0.154^{* * *}$ & $0.149^{* * *}$ \\
\hline & {$[0.000]$} & {$[0.000]$} & {$[0.000]$} & {$[0.000]$} \\
\hline \multirow[t]{2}{*}{ facilities } & $0.015^{* * *}$ & $0.015^{* * *}$ & $0.017^{* * *}$ & $0.016^{* * *}$ \\
\hline & {$[0.001]$} & {$[0.002]$} & {$[0.000]$} & {$[0.001]$} \\
\hline \multirow[t]{2}{*}{ access } & $-0.001^{* *}$ & $-0.001^{*}$ & $-0.002^{* * *}$ & $-0.002^{* * *}$ \\
\hline & {$[0.017]$} & [0.067] & {$[0.001]$} & {$[0.005]$} \\
\hline \multirow[t]{2}{*}{ urbanization } & $-0.028^{* * *}$ & $-0.024^{* * *}$ & $-0.032^{* * *}$ & $-0.032^{* \cdots *}$ \\
\hline & {$[0.003]$} & [0.009] & {$[0.001]$} & {$[0.003]$} \\
\hline \multirow[t]{2}{*}{ natura } & $-0.004^{* *}$ & $-0.004^{* *}$ & $-0.004^{* *}$ & $-0.004 *$ \\
\hline & [0.039] & {$[0.043]$} & {$[0.040]$} & [0.059] \\
\hline \multirow[t]{2}{*}{ Constant } & $-1.026^{* * *}$ & $-1.020^{* * *}$ & $-1.145^{* * *}$ & $-1.098^{* * *}$ \\
\hline & {$[0.001]$} & {$[0.001]$} & {$[0.001]$} & {$[0.001]$} \\
\hline R-squared & 0.3905 & 0.3919 & 0.3855 & 0.3855 \\
\hline Log likelihood & 550.83846 & 552.76408 & 549.54059 & 552.14411 \\
\hline AIC & -1079.677 & -1083.528 & -1077.081 & -1082.288 \\
\hline Observations & 542 & 542 & 542 & 542 \\
\hline \multicolumn{2}{|c|}{ Diagnostic tests for spatial dependence } & \multicolumn{2}{|c|}{ First-order border } & Inverse-square distance \\
\hline \multicolumn{2}{|c|}{ Moran's I (error) } & \multicolumn{2}{|c|}{$5.017^{* * *}$} & $6.261^{* * *}$ \\
\hline \multicolumn{2}{|c|}{ Lagrange multiplier (lag) } & \multicolumn{2}{|c|}{$24.925^{* * *}$} & $34.232^{* * *}$ \\
\hline \multicolumn{2}{|c|}{ Robust LM (lag) } & \multicolumn{2}{|c|}{$3.703^{*}$} & $5.051^{* *}$ \\
\hline \multicolumn{2}{|c|}{ Lagrange multiplier (error) } & \multicolumn{2}{|c|}{$21.471^{* * *}$} & $31.735^{* * *}$ \\
\hline \multicolumn{2}{|c|}{ Robust LM (error) } & \multicolumn{2}{|l|}{0.248} & 2.554 \\
\hline
\end{tabular}

Note: $\mathrm{p}$ values are shown in brackets.

**** $1 \%$ significance level.

** $5 \%$ significance level.

* $10 \%$ significance level.

Source: Compiled by the authors.

Table 4

Direct and indirect effects (spatial spillovers).

\begin{tabular}{|c|c|c|c|c|c|c|c|}
\hline & \multicolumn{3}{|c|}{ Square inverse distance } & \multicolumn{3}{|c|}{ First-order common border matrix } & \multirow{2}{*}{$\frac{\text { Square inverse distance }}{\text { Indirect effects/Total effects }}$} \\
\hline & Direct effects & Indirect effects & Total effects & Direct effects & Indirect effects & Total effects & \\
\hline pop & $-0.0419^{* * *}$ & $-0.0313^{* * *}$ & $-0.0732^{* * *}$ & $-0.0427^{* * *}$ & $-0.0154^{* * *}$ & $-0.0580^{* * *}$ & 0.4276 \\
\hline ageing & $-0.0271^{* * *}$ & $-0.0202^{* * *}$ & $-0.0473^{* * *}$ & $-0.0261^{* * *}$ & $-0.0094 * *$ & $-0.0355^{* * *}$ & 0.4271 \\
\hline contract & $0.0298^{* * *}$ & $0.0223^{* * *}$ & $0.0521^{* * *}$ & $0.0298^{* * *}$ & $0.0107^{* * *}$ & $0.0405^{* * *}$ & 0.4280 \\
\hline income & $0.1384^{\text {*k* }}$ & $0.1033^{\text {*** }}$ & $0.2417^{* * *}$ & $0.1391^{* k *}$ & $0.0501^{\text {*** }}$ & $0.1892^{* * *}$ & 0.4274 \\
\hline facilities & $0.0148^{* * *}$ & $0.0110^{* *}$ & $0.0258^{* * *}$ & $0.0157^{* * *}$ & $0.0056^{* * *}$ & $0.0213^{* * *}$ & 0.4264 \\
\hline access & $-0.0008^{*}$ & $-0.0006^{*}$ & $-0.0013^{*}$ & $-0.0010^{\star *}$ & $-0.0004^{* *}$ & $-0.0013^{* * *}$ & 0.4615 \\
\hline urbanization & $-0.0247^{* * *}$ & $-0.0185^{* *}$ & $-0.0432^{* * *}$ & $-0.0279^{* * *}$ & $-0.0101^{* *}$ & $-0.0380^{* * *}$ & 0.4282 \\
\hline natura & $-0.0038^{* *}$ & $-0.0028^{*}$ & $-0.0066^{* *}$ & $-0.0039^{* *}$ & $-0.0014^{*}$ & $-0.0053^{k *}$ & 0.4242 \\
\hline
\end{tabular}

${ }^{* * * *} 1 \%$ significance level.

** $5 \%$ significance level.

* $10 \%$ significance level.

Source: Compiled by the authors.

explanatory variables on surroundings than those with no population problems. These results are indicating that spread effects on territory have more impact on rural areas with depopulation risk. Policymakers should take note of these results and design policies to improve economic activity not only in municipalities at depopulation risk but also in the surrounding municipalities. Initiatives such as supporting commercial, service and knowledge hubs to serve small businesses in a certain municipality and its surroundings can boost population inflows to areas with demographic decline. The findings also suggest that policies aimed at improving accessibility in terms of both transport and information and communication technology infrastructures may tackle the depopulation loss suffered by certain municipalities. The spatial analysis and the spread effects highlight the importance of linkages between municipalities. Hence, interterritorial policies to ensure the efficient distribution of public resources are important. 


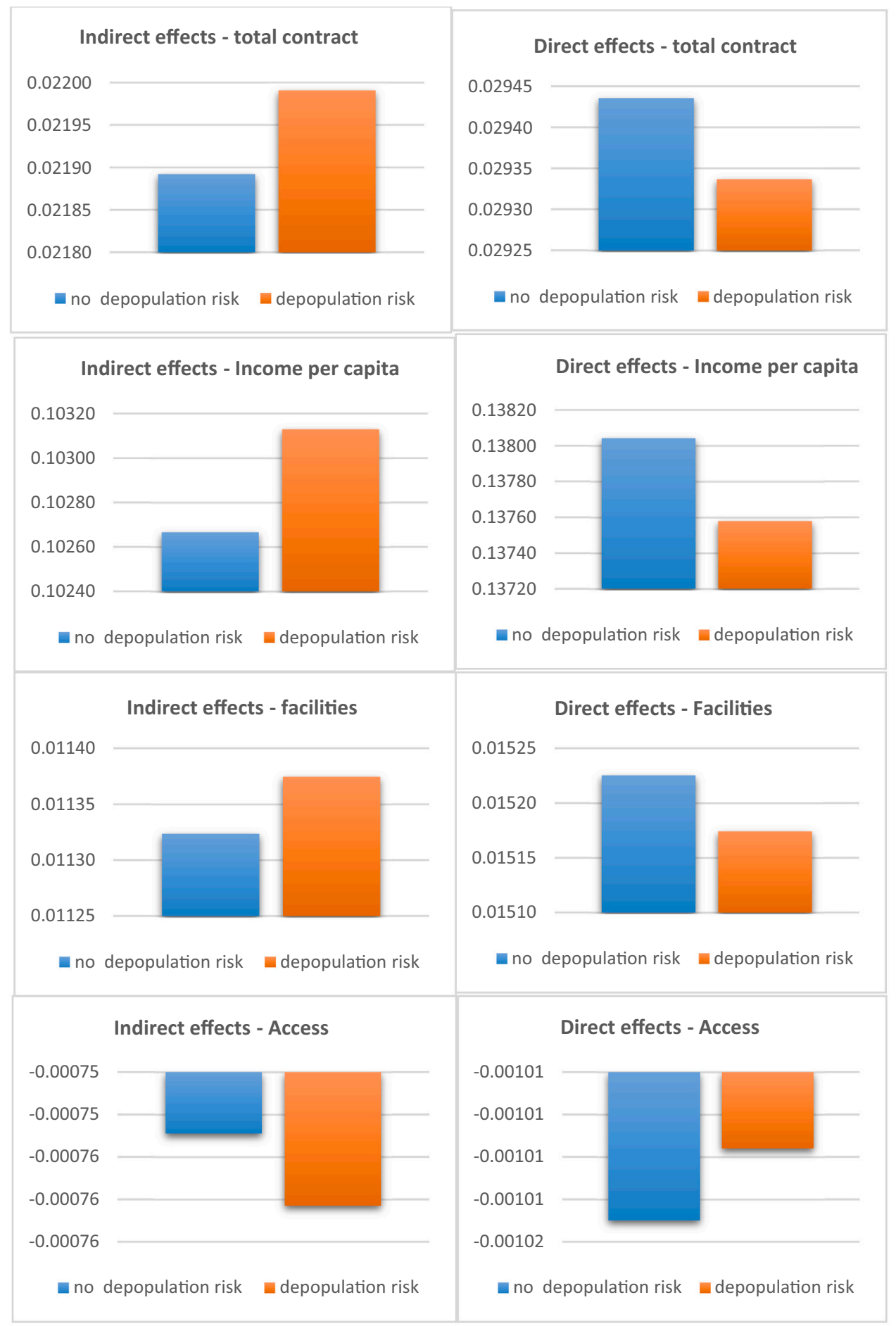

Fig. 5. Direct and indirect effects for areas considered with or without depopulation risk. Neighbourhood criteria based on the square inverse distance. Source: Compiled by the authors.

\section{Conclusions}

The analysis explores the population dynamics in the municipalities of a Southern European region. The model consistently tested the influence of variables that can be considered as crucial to drive population decline in large areas of the territory. Among observed drivers, accessibility, facilities, economic conditions, population ageing, natural amenities and the degree of urbanization are identified as factors to be considered and monitored in any regional strategy to face demographic challenges. What is relevant, the spatial approach, applied to a region where rural and urban communities spread across the territory, identifies a significant interdependence with neighbouring areas, and thereby highlights the importance of including interterritorial policies in this debate. Consequently, addressing the objectives raised at the beginning of this article, our findings support that demographic dynamics can be observed not only as a local issue but also as a reflection of spatial interactions among neighbouring communities. A systemic approach of anti-depopulation policies must put the focus on this extended territorial approach as demographic impacts of economic drivers, accessibility and public services are widened by a spatial dependence relationship, given the significance 
of the estimated indirect effects.

Three main features characterise the data set used for the modelling in this study. First, it comprises a large number of municipalities $(>500)$, more than 150 of which are at risk of depopulation. Second, it covers a range of geographical situations. Third, the region includes rural areas which face substantial demographic decline coexisting with growing urban areas. Although this region has an area of $23,255 \mathrm{~km}^{2}$ with an average density of more than 200 inhabitants $/ \mathrm{km}^{2}$, large swathes of land have low densities and are experiencing substantial population losses.

All model's variables show the expected sign except for the presence of natural areas, which shows a negative contribution to population growth. This result invites to reflect on whether or not protected areas could be perceived by local population as a constrain and not as an enhancer of population growth.

As expected, local economic conditions show a significant positive effect and a substantial contribution to population dynamics. Other variables matter, with accessibility and degree of urbanization showing relevant indirect effects. This result suggests that regional policy can focus not only on a given municipality but on its near surroundings, perhaps by promoting initiatives that support business hubs with improved transport municipalities. We cannot segment a rural municipality from its nearest urban area, so coping with depopulation should consider strengthening economic and social links between neighbouring rural and urban areas.

Estimated direct effects for the group of municipalities that don't face depopulation risk in the studied region are, on average, greater than direct effects observed in areas with depopulation problems. However, indirect effects in municipalities with depopulation risk are, on average, higher than indirect effects in municipalities with no demographic decline. This finding confirms that tackling the demographic problem in declining municipalities calls for targeting not only such municipalities but also their nearest surroundings.

Our findings support a territorially balanced strategy of enhancing competitiveness, creating new job opportunities, and stimulating entrepreneurship. They can support the implementation of regional and national plans to enhance attractiveness, in line with the proposals of the European Parliament that demand particular support to clusters of local administrative units that fulfil certain conditions (European Parliament, 2017), which is relevant for the new programming period for the EU structural funds (2021-2027). From a spatial point of view, our approach supports a deeper focus on policy measures targeted to territorial clusters, such as those identified in the LISA map or those areas subjected to substantial population decline and their neighbour more urbanized areas.

Our results do not neglect the relevance of bottom-up local development policies. However, these policies should take into account the spillover effects across territorial systems, which open the door to cooperation with the regional administration's strategy as well as among municipalities. The significance of the indirect spatial effects supports other authors' assertions (Torre, 2019) that regional strategies based on cooperation rather than competition among neighbouring municipalities are called for in many areas to improve employment, economic diversification and connectivity. A territorial regional view should be incorporated into local plans, even if they apparently affect only a small number of municipalities. Furthermore, the research provides a method to measure the significance of spatial indirect effects, through a spatial growth modelling approach that can be useful to monitor the success of policies, oriented to specific territorial clusters.

This article and its limitations create openings for further research. One drawback of the study is that while the spatial interdependence among neighbouring municipalities is clearly reflected, further theoretical and empirical discussions on social mechanisms behind such interdependence become necessary. Aspects to be considered in further studies are social capital, entrepreneurship and social innovation. Another opportunity is the analysis of spillover or dependence effects due to employment growth in urban and semi-urban areas (or areas not at population risk) that are not neighbouring or close to rural areas (or at-risk areas) with population change. The method could be also applied to the estimation of cross-border effects between two neighbouring regions (called Comunidades Autónomas in Spanish). Finally, this contribution opens a possibility to enrich discussions with local stakeholders at the regional and local communities' levels. Thus, the quantitative approach can be in parallel with qualitative approaches that supply field-based solutions for local problems. In summary, this article offers an approach to assess regional policies, from the strategic perspective of relevant administrations, that target areas where economic decisions enable effects that spread to surrounding areas.

\section{CRediT authorship contribution statement}

Conceptualization: Budí, V., Roig-Tierno, N. and García-ÁlvarezCoque, J.M.

Methodology: Alamá-Sabater, L., García-Álvarez-Coque, J.M.

Software: Alamá-Sabater, L.

Data curation: Alamá-Sabater, L., García-Álvarez-Coque, J.M.

Writing - Original draft: Alamá-Sabater, L., García-Álvarez-Coque, J.M.

Investigation: Alamá-Sabater, L., Budi, V., Roig-Tierno, N. and García-Álvarez-Coque, J.M.

Supervision: Alamá-Sabater, L., Budi, V., Roig-Tierno, N. and García-Álvarez-Coque, J.M.

Validation: Alamá-Sabater, L., Budi, V., Roig-Tierno, N. and GarcíaÁlvarez-Coque, J.M.

Writing - Reviewing and editing: Alamá-Sabater, L., GarcíaÁlvarez-Coque, J.M.

Visualization: Alamá-Sabater, L., Budi, V., Roig-Tierno, N. and García-Álvarez-Coque, J.M.

\section{Acknowledgments}

Luisa Alamá-Sabater acknowledge the financial support of the Spanish Ministerio de Economía y Competitividad (ECO2017-85746-P), Generalitat Valenciana (HIECPU/2020/1) and Universitat Jaume I (UJIB2020-57). Authors also acknowledge support by the inter-university project of dissemination to stakeholders called Càtedra AVANT (antidepopulation agenda), funded by Generalitat Valenciana.

Annex. Indicators and thresholds to define depopulation risk

\begin{tabular}{|c|c|c|}
\hline Indicator & Description & Threshold \\
\hline Population density & Inhabitants $/ \mathrm{km}^{2}$ & $\leq 20$ \\
\hline Demographic growth (1996-2016) & Growth rate between 1996 and $2016(\%)$ & $\leq 0$ \\
\hline Vegetative growth & Percentage of vegetative change (1996-2015) as a percentage of total population (\%) & $\leq-10$ \\
\hline Ageing rate & Population $>64$ years divided by population $<16$ years $(\%)$ & $\geq 250$ \\
\hline Dependence index & Population $<16$ years and $>64$ years divided by population between 16 and 64 years (\%) & $\geq 60$ \\
\hline Migratory rate & Migratory balance in $2006-2016$ divided by total population in $2016(\%)$ & $\leq 0$ \\
\hline
\end{tabular}


Depending on the value of the selected demographic indicators, the municipalities can be classified according to depopulation risk: Very high risk is used when the municipality meets the criteria for all indicators; High risk is used when the criteria are met for five indicators; Moderate risk is used when the criteria are met for four indicators or when the population of the municipality is less than or equal to 100 inhabitants.

Other is the term used when a municipality meets the criteria for fewer than four indicators and the population is greater than 100 inhabitants.

Source: List of indicators proposed by Generalitat Valenciana (2017a). Quoted by Alamá-Sabater et al. (2019).

\section{References}

Alamá-Sabater, L., Budí, V., García-Álvarez-Coque, J. M., \& Roig-Tierno, N. (2019). Using mixed research approaches to understand rural depopulation. Economía Agraria y Recursos Naturales, 19(1), 99-120. https://doi.org/10.7201/ earn.2019.01.05.

Amcoff, J., \& Westholm, E. (2007). Understanding rural change demography as a key to the future. Futures, 39(4), 363-379.

Anselin, L. (1988). Spatial econometrics: Methods \& models. Springer.

Anselin, L. (2017). Spatial regression. Retrieved from https://spatial.uchicago.edu/si tes/spatial.uchicago.edu/files/10_specification_tests_2_slides.pdf.

Anselin, L., \& Bera, A. K. (1998). Spatial dependence in linear regression models with an introduction to spatial econometrics. Statistics: Textbooks and Monographs, 155, 237-289.

Boarnet, M., Chalermpong, S., \& Geho, E. (2005). Specification issues in models of population \& employment growth. Papers in Regional Science, 84(1), 21-46.

Boarnet, M. G. (1994). The monocentric model and employment location. Journal of Urban Economics, 36, 79-97.

Burholt, V., \& Dobbs, C. (2012). Research on rural ageing: Where have we got to and where are we going in Europe? Journal of Rural Studies, 28(4), 432-446.

Burillo, M. P., Rubio Terrado, P., \& Burillo Mozota, F. (2019). Strategies facing the depopulation of the Serrania Celtibérica within the framework of the European cohesion policy 2021-2027. Economía Agraria y Recursos Naturales, 19(1), 83-97. https://doi.org/10.7201/earn.2019.01.05.

Camarero, L., \& Sampedro, R. (2019). Transnational rurality \& depopulation: Recession and settle down in rural Castilla y León. Economía Agraria y Recursos Naturales, 19(1), 59-82. https://doi.org/10.7201/earn.2019.01.04.

Cheshire, P., \& Magrini, S. (2006). Population growth in European cities: Weather matters - But only nationally. Regional Studies, 40, 23-37.

Cheshire, P., \& Magrini, S. (2009). Urban growth drivers in a Europe of sticky people and implicit boundaries. Journal of Economic Geography, 9, 85-115.

Chi, G., \& Marcouiller, D. (2011). Isolating the effect of natural amenities on population change at the local level. Regional Studies, 45(4), 491-505.

Chi, G., \& Zhu, J. (2008). Spatial regression models for demographic analysis. Population Research and Policy Review, 27(1), 17-42.

Clark, D., Kahn, J., \& Ofek, H. (1988). City size, quality of life, \& the urbanization deflator of the GNP: 1910-1984. Southern Economic Journal, 54(3), 701-714.

Collantes, F., \& Pinilla, V. (2004). Extreme depopulation in the Spanish rural mountain areas: A case study of Aragon in the nineteenth and twentieth centuries. Rural History, 15(2), 149-166.

Collantes, F., \& Pinilla, V. (2011). Peaceful surrender: The depopulation of rural Spain in the twentieth century. Cambridge Scholars Publishing.

Collantes, F., Pinilla, V., Sáez, L. A., \& Silvestre, J. (2014). Reducing depopulation in rural Spain: The impact of immigration. Population, Space and Place, 20(7), 606-621.

Cushing, B. (1987). A note on the specification of climate in models of population migration. Journal of Regional Science, 27, 641-649.

de Graaff, T., van Oort, F. G., \& Florax, R. J. (2012a). Regional population-employment dynamics across different sectors of the economy. Journal of Regional Science, 52(1), $60-84$.

de Graaff, T., Van Oort, F. G., \& Florax, R. J. G. M. (2012b). Regional populationemployment dynamics across different sectors of the economy. Journal of Regional Science, 52(1), 60-84.

Delfmann, H., Koster, S., McCann, P., \& Van Dijk, J. (2014). Population change \& new firm formation in urban \& rural regions. Regional Studies, 48(6), 1034-1050.

Dijkstra, L., \& Poelman, H. (2014). A harmonised definition of cities and rural areas: The new degree of urbanization. WP 01/2014. European Commission.

Elhorst, P. (2010). Applied spatial econometrics: Raising the bar. Spatial Economic Analysis, 5(1).

European Parliament. (2017). Resolution of 14 November 2017 on the deployment of cohesion policy instruments by regions to address demographic change (8 TA(2017) 0427).

European Parliament. (2018). European Parliament resolution of 3 October 2018 on addressing the specific needs of rural, mountainous \& remote areas (2018/2720(RSP)).

Eurostat. (2019). Methodological manual on territorial typologies. Luxembourg: Publications Office of the European Union.

Ferry, M., \& Vironen, H. (2011). Dealing with demographic change: Regional policy responses. Geopolitics, History and International Relations, 3(1), 25-58.

Feser, E., \& Isserman, A. (2006). Harnessing growth spillovers for rural development: The effects of regional spatial structure. In Report to USDA rural development. University of Illinois at Urbana-Champaign.
Firmino, D., Silva, C., Elhorst, P., \& Mota, R. (2017). Urban \& rural population growth in a spatial panel of municipalities. Regional Studies, 51(6), 894-908.

Generalitat Valenciana. (2017a). Agenda Valenciana Antidespoblament (AVANT). Propuesta de Sistema de Indicadores. Gabinet del President. Generalitat Valenciana. 22 November 2017.

Generalitat Valenciana. (2017b). Portal Estadístico de la Generalitat Valenciana. http://www.pegv.gva.es/es/informacion-estadistica. (Accessed January 2019).

Glaeser, E., Kallal, H., Scheinkman, J., \& Shleifer, A. (1992). Growth in cities. The Journal of Political Economy, 100(6), 1126-1152.

Glaeser, E., Kolko, J., \& Saiz, A. (2001). Consumer city. Journal of Economic Geography, 1 (1), 27-50.

Glaeser, E., Scheinkman, J., \& Shleifer, A. (1995). Economic growth in a cross-section of cities. Journal of Monetary Economics, 36(1), 117-143.

Glaeser, E., \& Shapiro, J. (2003). Urban growth in the 1990s: Is city living back? Journal of Regional Science, 43(1), 139-165.

Gobierno de España. (2019). Diagnóstico de la estrategia nacional frente al reto demográfico. Madrid: Comisionado del Gobierno frente al reto demográfico. Ministerio de Política Territorial y Función Pública.

Graves, P. (1979). A life-cycle empirical analysis of migration and climate by race. Journal of Urban Economics, 6, 135-147.

Graves, P. (1983). Migration with a composite amenity. Journal of Regional Science, 23, $541-546$.

Graves, P., \& Linneman, P. (1979). Household migration: Theoretical and empirical results. Journal of Urban Economics, 6, 383-404.

Han, M., Hakansson, J., \& Ronnegard, L. (2016). To what extend do neighbouring populations affect local population growth over time? Population, Space and Place, 22 (1), 68-83.

Henry, M. S., Schmitt, B., Kristensen, K., Barkley, D. L., \& Bao, S. (1999). Extending Carlino-Mills models to examine urban size and growth impacts on proximate rural areas. Growth and Change, 30(4), 526-548.

Henry, M. S., Schmitt, B., \& Piguet, V. (2001). Spatial econometric models for simultaneous systems: Application to rural community growth in France. International Regional Science Review, 24(2), 171-193.

Jedwab, R., Christiaensen, L., \& Gindelsky, M. (2017). Demography, urbanization and development: rural push, urban pull and... urban push? Journal of Urban Economics, 98(C), 6-16.

LeSage, J., \& Pace, K. (2009). Motivating and interpreting spatial econometric models, in Introduction to spatial econometrics, ed. Taylor \& Francis Group.

Lunberg, J. (2002). Using spatial econometrics to analyses local growth in Sweden. Journal of Regional Studies, 40(3), 303-316.

Lundberg, J. (2002). Using spatial econometrics to analyze local growth in Sweden. Centre for Regional Science, Umea University.

Pacheco, A. I., \& Tyrrell, T. (2002). Testing spatial patterns and growth spillovers effects in clusters of cities. Journal of Geographical Systems, 4(83), 275-285.

Pinilla, V., Ayuda, M. I., \& Sáez, L. A. (2008). Rural depopulation and the migration turnaround in Mediterranean Western Europe: A case study of Aragon. Journal of Rural and Community Development, 3(1).

Polèse, M., \& Shearmur, R. (2006). Why some regions will decline: A Canadian case study with thoughts on local development strategies. Papers in Regional Science, 85(1), 23-26.

Portnov, B., \& Schwartz, M. (2008). On the relativity of urban location. Regional Studies, 42(4), 605-615.

Royuela, V. (2011). Modelling quality of life \& population growth. The case of the Barcelona Metropolitan area. Spatial Economic Analysis, 6(1), 83-109.

Royuela, V., Moreno, R., \& Vaya, E. (2010). Influence of quality of life on urban growth: A case of study of Barcelona, Spain. Regional Studies, 44(5), 551-567.

Royuela, V., Suriñach, J., \& Reyes, M. (2003). Measuring quality of life in small areas over different periods of time. Social Indicators Research, 64(1), 51-74.

Shapiro, J. (2006). Smart cities: Quality of life, productivity, and the growth effects of human capital. The Review of Economics and Statistics, 88(2), 324-335.

Shields, M., Goetz, S., \& Wang, Q. (2005). Out-migration from the Northeast US: The relative roles of economic \& amenity differentials. In G. Green, S. Deller, \& D. Marcouiller (Eds.), Amenities \& rural development: Theory, methods \& public policy (pp. 78-94). Northampton, MA: Edward Elgar.

Tong, T., Yu, T. E., Cho, S., Jensen, K., \& De La Torre, D. (2013). Evaluating the spatial spillover effects of transportation infraestructures on agricultural output across the United States. Journal of Transport Geography, 30, 47-55.

Torre, A. (2019). Territorial development and proximity relations. In R. Capello, \& P. Nijkamp (Eds.), Handbook of regional and development theories (pp. 326-343). Cheltenham: Edward Elgar Publishing.

Instituto Nacional de Estadística. Spanish Statistics Institute (INE). www.ine.es. 